Original Research Paper

\title{
Microstructural characterization of medical-grade stainless steel powders prepared by mechanical alloying and subsequent annealing
}

\author{
E. Salahinejad ${ }^{\text {a,* }}$, M.J. Hadianfard ${ }^{\mathrm{a}}$, M. Ghaffari ${ }^{\mathrm{b}}$, R. Amini $^{\mathrm{c}}$, Sh. Bagheri Mashhadi $^{\mathrm{a}}$, A.K. Okyay $^{\mathrm{b}}$ \\ ${ }^{a}$ Department of Materials Science and Engineering, School of Engineering, Shiraz University, Zand Blvd., 7134851154 Shiraz, Iran \\ ${ }^{\mathrm{b}}$ Department of Electrical and Electronics Engineering, UNAM - National Institute of Materials Science and Nanotechnology, Bilkent University, Ankara 06800, Turkey \\ c Department of Materials Science and Engineering, Shiraz University of Technology, Modarres Blvd., 3619995161 Shiraz, Iran
}

\section{A R T I C L E I N F O}

\section{Article history:}

Received 3 August 2012

Received in revised form 18 October 2012

Accepted 6 November 2012

Available online 3 December 2012

\section{Keywords:}

Microstructure

Nanostructured materials

Medical-grade stainless steel

Mechanical alloy

Annealing

\begin{abstract}
A B S T R A C T
The harmful effect of nickel ions released from conventional stainless steel implants has provided a high level of motivation for the further development of nickel-free stainless steels. In this paper, the microstructure of medical-grade nickel-free stainless steel powders, with the chemical composition of ASTM F2581, is studied during mechanical alloying and subsequent annealing. Rietveld X-ray diffraction and transmission electron microscopy evaluations reflect nanocrystallization, austenitization and amorphization of the powders due to mechanical activation. It is also realized that annealing of the as-milled powder can develop a single austenitic structure with nanometric crystallite sizes, implying a considerable inherent resistance to grain growth. This study demonstrates the merit of mechanical alloying and subsequent annealing in the development of nanostructured medical-grade stainless steels.

(C) 2012 The Society of Powder Technology Japan. Published by Elsevier B.V. and The Society of Powder Technology Japan. All rights reserved.
\end{abstract}

\section{Introduction}

Austenitic stainless steels, typically AISI 316L, are conventionally utilized in orthopedics; nonetheless, problems have been realized with theses medical grade alloys. The most important problem is the harmful effect of nickel ions released from the implants due to corrosion, wear and so on [1], providing a high level of motivation for the further development of nickel-free ones. In ASTM standards, two nickel-free medical grade stainless steels have been imported: ASTM F2229 and ASTM F2581. In the recent years, a number of in vitro and in vivo studies have been conducted on ASTM F2581 alloy, typically from the viewpoints of biocompatibility, osseointegration, and corrosion behaviors [2-7].

On the other hand, nanomaterials have been the subject of widespread researches over recent decades. Nanocrystalline materials are structurally characterized by a large volume fraction of grain boundaries, which may significantly alter their physical, mechanical, and chemical properties in comparison with conventional coarse-grained polycrystalline materials [8]. It is well established that mechanical alloying (MA) is a capable process to synthesize a wide variety of equilibrium and non-equilibrium structures including nanostructured and amorphous powders. MA is a solid-state powder processing technique involving repeated welding, fracturing, and rewelding of powder particles in a high-energy ball mill [9].

\footnotetext{
* Corresponding author. Tel.: +98 917 3879390; fax: +98 7112307293.

E-mail address: erfan.salahinejad@gmail.com (E. Salahinejad).
}

There are a number of reports on mechanical alloying of nickelfree stainless steel, dealing with nanocrystallization, austenitization, and amorphization, for instance Refs. [10,11]. Additionally, liquid-phase sintering of mechanically-alloyed stainless steel powders, with the chemical composition of ASTM F2581, using a Mn-Si sintering aid has been detailed recently [12-14]. However, no work has been reported on its detailed structural evolution during mechanical alloying and subsequent annealing. In this research, the mechanical alloying and austenitization behaviors of ASTM F2581 stainless steel powders are investigated via Rietveld X-ray diffraction and transmission electron microscopy.

\section{Experimental}

Elemental powders of $\mathrm{Fe}, \mathrm{Cr}, \mathrm{Mn}, \mathrm{Mo}, \mathrm{Si}$, and $\mathrm{C}$ (supplied by Merck) and iron nitride powder $\left(\mathrm{Fe}_{x} \mathrm{~N} ; x=2-4\right.$, supplied by Alfa Aesar) with the nominal composition of Fe-17Cr-10Mn-3Mo$0.4 \mathrm{Si}-0.5 \mathrm{~N}-0.2 \mathrm{C}$ (wt.\%) (ASTM F2581) were used as the raw materials. Our quantitative XRD studies on the as-received nitride powder showed that it is composed of $\mathrm{Fe}_{3} \mathrm{~N}$ and $\mathrm{Fe}_{4} \mathrm{~N}$ compounds, where $x=3.27$ at $\mathrm{Fe}_{x} \mathrm{~N}$ (the calculated nitrogen content was confirmed by LECO). Milling was performed by using a Sepahan planetary ball mill under an argon atmosphere with a ball-to-powder weight ratio of $20: 1$ at a rotation speed of $500 \mathrm{rpm}$ for $24,48,72$, 96 , and $120 \mathrm{~h}$, in a tempered steel bowl (capacity $=150 \mathrm{~mL}$ ). 4 bearing steel balls of $20-\mathrm{mm}$ and 12 bearing steel balls of $8-\mathrm{mm}$ 
diameters with a chemical composition of $\mathrm{Fe}-1.5 \mathrm{Cr}-0.9 \mathrm{C}-0.8 \mathrm{Si}-$ $0.5 \mathrm{Mn}$ were used in this work.

The structures were characterized by X-ray diffraction experiments (XRD, Shimadzu Lab X-6000 with $\mathrm{Cu} \mathrm{K} \alpha$ radiation) with a step size of $0.03^{\circ}$ and a step time of $4 \mathrm{~s}$. The XRD qualitative and quantitative analyses were conducted by X'Pert HighScore and MAUD programs respectively. The MAUD software employs the Rietveld refinement to estimate the crystallite sizes (by the Double-Voigt approach) and the amorphous contents. The latter was determined by analyzing the XRD data of a mixture of the milled powders and a standard, with the weight ratio of 75:25. In this work, Mn powders milled for $5 \mathrm{~h}$ with an average crystallite size of $23 \mathrm{~nm}$ were employed as the standard, because Mn has an $\mathrm{X}$-ray mass attenuation coefficient close to the stainless steel; milling of the Mn powder also increases the size compatibility of the mixture components. In addition, a transmission electron microscope (TEM, FEI-Tecnai G2F30) was used to investigate the structure and XRD results validity.

To obtain a single austenitic structure which is of the essential requirements of implants, the selective as-milled powders were encapsulated in evacuated quartz tubes $\left(10^{-3} \mathrm{~atm}\right)$, annealed at $1000,1050,1100,1150,1200,1250$, and $1300^{\circ} \mathrm{C}$ for $90 \mathrm{~min}$, immediately water-quenched, and characterized via XRD.

\section{Results and discussion}

Fig. 1a presents the XRD pattern of the stainless steel powders milled for the different milling durations. No characteristic peak of the constituent elements and nitride used was detected in the XRD data, i.e. mechanical activation introduced by milling is enough for the complete break-up and dissolution of the nitride and elements into the iron lattice. The presence of crystalline ferrite $(\alpha)$ and austenite $(\gamma)$ phases is recognized in the XRD data. Since the amount of the $\alpha$ phase, as shown below, is low, its reflections cannot be observed and its presence could be merely detected by the Rietveld method.

To analyze quantitatively the XRD date, the MAUD Rietveld method was employed. Typically, Fig. $1 \mathrm{~b}$ and $\mathrm{c}$ demonstrates the XRD pattern and fitting curve obtained by Rietveld-analyzing the mixture of the $120 \mathrm{~h}$ milled stainless steel powder and the standard, where a satisfactory fitting is observed between the experimental and calculated patterns. The weight percentage of the amorphous phase $(A)$ is estimated by the following equation [10]:

$A=\frac{1-\left(W_{s} / R_{s}\right)}{100-W_{z}} \times 10^{4}$

where $W_{s}$ is the percentage of the standard mixed (i.e. $W_{s}=25 \%$ ) and $R_{S}(\%)$ is that measured by the Rietveld analysis. Obviously, always $W_{s} \leqslant R_{s}$, because the XRD quantitative phase analysis cannot directly consider the amorphous phase. The $\alpha$ and $\gamma$ phase fractions calculated by the Rietveld analysis multiplied by $(100-A)$ is the actual percentage of the $\alpha$ and $\gamma$ phases in the as-milled powders. The results of the XRD analyses on the as-milled powders are summarized in Table 1, in which three phenomena are noticeable: nanocrystallization, austenitization and amorphization.

The bright-field TEM micrograph and selected area diffraction (SAD) pattern of the stainless steel powder milled for $120 \mathrm{~h}$ are provided in Fig. 2a. The TEM micrograph includes nano-sized dark regions embedded in a bright matrix. It is noteworthy that in bright-field TEM images those crystallites which are close to a zone-axis orientation appear dark; in contrast, all crystallites which are far off a zone-axis orientation appear bright like amorphous phases. The SAD pattern contains diffraction spots of the crystalline phases and the halo pattern of the amorphous phase, suggesting that the material has an amorphous/nanocrystalline
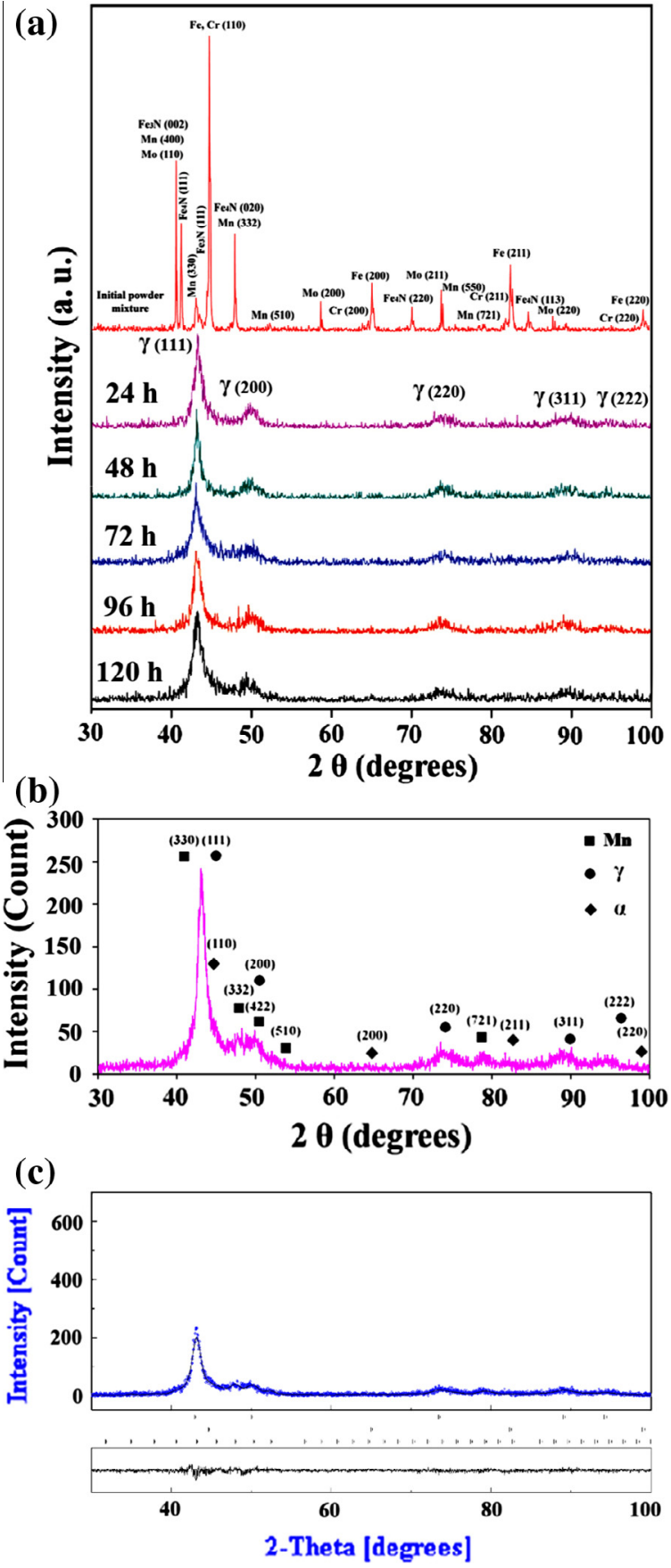

Fig. 1. XRD pattern of the stainless steel powders milled for the different durations (a), XRD pattern (b) and fitting curve (c) of the $120 \mathrm{~h}$ milled stainless steel powder mixed with the Mn standard.

Table 1

Results of the XRD analyses on the as-milled powders.

\begin{tabular}{rllllll}
\hline \multirow{2}{*}{ Milling time $(\mathrm{h})$} & \multicolumn{2}{l}{ Phase percentage } & & \multicolumn{2}{l}{ Crystallite size $(\mathrm{nm})$} \\
\cline { 2 - 4 } & Ferrite & Austenite & Amorphous & & Ferrite & Austenite \\
\hline 24 & 10.3 & 44.8 & 44.9 & & 12.1 & 14.4 \\
48 & 10.1 & 47.9 & 42 & & 11.5 & 11.9 \\
72 & 9.8 & 42.3 & 47.9 & & 10.7 & 9.4 \\
96 & 8.5 & 40.9 & 50.6 & & 10.0 & 9.3 \\
120 & 7.4 & 40.6 & 52 & & 9.9 & 8.9 \\
\hline
\end{tabular}

structure. Since the amorphous phase content is not considerable, individual SAD patterns of the crystalline and amorphous phases 

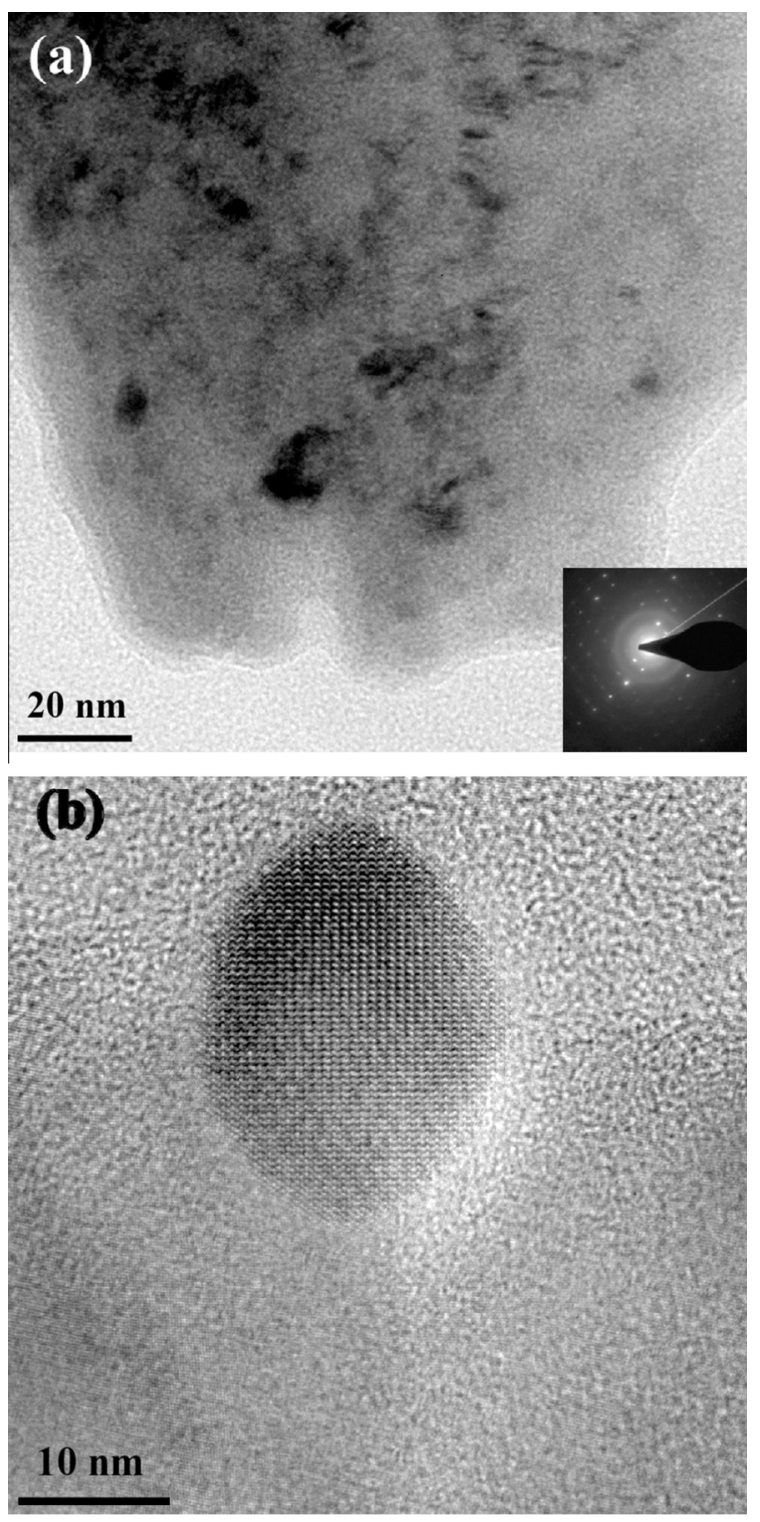

Fig. 2. TEM micrograph and SAD pattern of the stainless steel powder milled for $120 \mathrm{~h}$ (a). Related high-resolution TEM (b) where the atomic arrangement consideration indicates a crystalline zone embedded in the amorphous matrix.

could not be taken. Fig. $2 \mathrm{~b}$ shows the high-resolution TEM micrograph of the stainless steel powder milled for $120 \mathrm{~h}$, in which the atomic arrangement consideration shows a nanocrystal embedded in the amorphous matrix. In addition, the crystalline regions embedded in the amorphous matrix and the presence of an amorphous band at the edge of the powder particle (Fig. 2b) the heterogeneous nucleation of the amorphous phase from grain boundaries of the crystalline phases and the external surface of the particles as high-energy places which are preferential for nucleation $[15,16]$. It can be also concluded that the TEM and XRD results are in good agreement. The observed structural transitions are discussed as follows.

\subsection{Nanocrystallization}

The substantial grain refinement during milling is explained by the well-established phenomenon of severe plastic deformation applied due to the actions of the milling media [9]. Furthermore, the role of the interstitially dissolved elements ( $C$ and $N$ ) in the accelerated structural refinement is noticeable. Nitrogen [10] and carbon [17] atoms are segregated at dislocations and grain boundaries, fixing the dislocations and stabilizing the grain boundaries. Consequently, the trickling down of mobile dislocations on the fixed dislocations contributes to the nucleation of new boundaries and a severe grain refinement. A similar contribution to structural refinement has been attributed to the interstitial dissolution of boron in mechanically alloyed cobalt-based powders [18].

\subsection{Austenitization}

The formation of the austenite phase in the powders originates from the dissolution of the austenite stabilizer elements (Mn and particularly $\mathrm{C}$ and $\mathrm{N}$ ) into the iron lattice. Moreover, the structural refinement to the nanometric scale favors the austenitization transition. Clearly, the grain refinement increases the volume fraction of interfaces (grain boundaries). Since the austenite/austenite interface has a smaller energy than the ferrite/ferrite and austenite/ferrite interfaces, austenitization is favorable [17]. Note that the initial increase in the austenite content suggests that the ferrite-to-austenite transformation prevails over amorphization; on the contrary, the subsequent decrease is indicative of the domination of the latter on the former.

\subsection{Amorphization}

It is considered from several viewpoints, as follows:

(a) Severe plastic deformation: The severe plastic deformation and extreme structural refinement occurring during milling increase the density of defects and the constraints of neighboring crystallites, thereby decreasing the stability of the crystalline structure and promoting amorphization [10,19].

(b) Atomic size mismatch: A large atomic size mismatch among the constituent elements induces significant strains to the lattice and increases the strain and free energy of crystalline phase. This effect can cause the crystals free energy to exceed the amorphous free energy, encouraging amorphization $[11,20]$. Particularly, carbon and nitrogen have considerable atomic size differences with the other constituent elements ( $\mathrm{Fe}, \mathrm{Cr}, \mathrm{Mn}, \mathrm{Mo}, \mathrm{Si}, \mathrm{N}$, and $\mathrm{C}$ atoms are 156,166 , $161,190,111,56$, and $67 \mathrm{pm}$ in size).

(c) Heat of mixing: a negative enthalpy of mixing among the constituent elements dictates a strong interaction among them and a better atomic level intermixing, thereby providing the driving force for amorphization [21]. Indeed, this effect prevents the formation of more stable phases like nitrides and carbides compared to the metastable amorphous phase. Particularly, when $\mathrm{Cr}$, Mn, Mo with a high affinity for $\mathrm{N}$ and $\mathrm{C}$ are added to the alloys, the intermixing of the constituent elements and amorphization readily occur. The observed slower kinetics of amorphization compared to Ref. [10] is due to the fact that in this work the milling system is closed; nevertheless, in the work of Ref. [10] milling was accomplished under a nitrogen atmosphere, where the content of nitrogen having a major contribution to amorphization increases progressively.

To obtain a single austenitic structure, the $120 \mathrm{~h}$ milled powder was heat-treated at 1000,1050,1100,1150,1200,1250, and $1300{ }^{\circ} \mathrm{C}$. The ferritescope measurements showed that only the temperatures of 1150,1200 , and $1250{ }^{\circ} \mathrm{C}$ yield a nonmagnetic structure which is of the essential requirements of orthopedic implants. According to the XRD analyses, annealing at the lower and higher temperatures leads to the existence of an amount of alpha $(\alpha)$ and delta $(\delta)$ ferrite accompanied by austenite $(\gamma)$ respectively. 


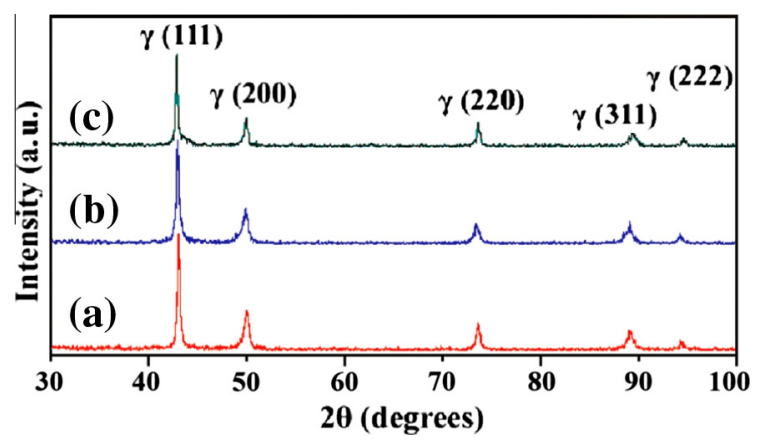

Fig. 3. XRD trace of the $120 \mathrm{~h}$ milled powder heat-treated at 1150 (a), 1200 (b), and 1250 (c) ${ }^{\circ} \mathrm{C}$.

Table 2

Results of the XRD analyses on the $120 \mathrm{~h}$ milled powder heat-treated.

\begin{tabular}{llll}
\hline \multirow{2}{*}{$\begin{array}{l}\text { Annealing } \\
\text { temperature }\end{array}$} & \multicolumn{2}{l}{ Phase percentage } & Austenite crystallite size (nm) \\
\cline { 2 - 3 } & Ferrite & Austenite & \\
\hline 1150 & 4 & 96 & 74 \\
1200 & 3 & 97 & 92 \\
1250 & 6 & 94 & 114 \\
\hline
\end{tabular}

The ferrite phases ( $\alpha$ and $\delta$ ) should not exist in implants, not only from the viewpoint of corrosion resistance but also because ferrite is a magnetic phase and magnetic alloys may be dislodged in magnetic fields [22]. The XRD pattern of the nonmagnetic samples, i.e. heat treated at 1150,1200 , and $1250{ }^{\circ} \mathrm{C}$ is illustrated in Fig. 3. The results of the XRD quantitative analysis are also listed in Table 2, indicating that the ferrite content is negligible. It is noteworthy that annealing at $1150{ }^{\circ} \mathrm{C}$ develops a structure of $74 \mathrm{~nm}$ in crystallite size, which reflects a considerable thermal stability and an inherent resistance to grain growth. The high thermal stability of these mechanically-alloyed powders against grain growth has been confirmed by TEM observations [13,14]. Typically, Cisneros et al. [23] reported austenite grain sizes smaller than $70 \mathrm{~nm}$ for mechanically alloyed $\mathrm{Fe}-18 \mathrm{Cr}-11 \mathrm{Mn}-(0.27-2.47) \mathrm{N}$ stainless steel nanostructures after annealing at $900,1000,1100$, and $1200^{\circ} \mathrm{C}$ for $2 \mathrm{~h}$. It is known that grain growth is strongly controlled by grain boundary diffusion and mobility. The factors affecting grain boundary mobility in nanostructured materials include grain boundary segregation, solute impurity, porosity, chemical ordering, and second phases. Indeed, in this study, solute drag effects combined with the typical contribution of carbon and nitrogen are expected to retard grain growth. The solubility of the interstitially dissolved atoms of nitrogen and carbon in the crystalline phases is limited; thus, they tend to segregate at grain boundaries to decrease strain energy, thereby retarding grain boundary mobility [24]. Studies on liquid-phase sintering of this type of medical-grade, mechanically-alloyed powders have shown that by using a eutectic Mn-Si alloy as a sintering aid, a proper densification and homogeneous distribution of the elements in the structure can be obtained [12-14].

\section{Summary}

Rietveld XRD and TEM analyses were conducted on ASTM F2581 stainless steel powders synthesized by mechanical alloying. It was realized that the as-milled powders consist of the amorphous, ferrite and austenite phases; and annealing under vacuum at 1150,1200 , and $1250{ }^{\circ} \mathrm{C}$ yields austenitic nanostructures. This study introduces a promising research field, namely ASTM F2581 nanostructures, opening up the clinical development of nanostructured implants in the near future.

\section{References}

[1] K. Yang, Y. Ren, Nickel-free austenitic stainless steels for medical applications, Sci. Technol. Adv. Mater. 11 (2010) 1-13.

[2] U.I. Thomann, P.J. Uggowitzer, Wear-corrosion behavior of biocompatible austenitic stainless steels, Wear 239 (2000) 48-58.

[3] M. Fini, A.N. Nicoli, P. Torricelli, G. Giavaresi, V. Borsari, H. Lenger, J. Bernauer, R. Giardino, R. Chiesa, A. Cigada, A new austenitic stainless steel with negligible nickel content: an in vitro and in vivo comparative investigation, Biomaterials 24 (2003) 4929-4939.

[4] L. Montanaro, M. Cervellati, D. Campoccia, C. Renata Arciola, Promising in vitro performances of a new nickel-free stainless steel, J. Mater. Sci.: Mater. Med. 17 (2006) 267-275.

[5] Y. Ren, H. Yang, K. Yang, B. Zhang, In vitro biocompatibility of a new high nitrogen nickel free austenitic stainless steel, Key Eng. Mater. 342-343 (2007) 605-608.

[6] R.F.V.V. Jaimes, M.L.C.A. Afonso, S.O. Rogero, S.M.L. Agostinho, C.A. Barbosa, New material for orthopedic implants: electrochemical study of nickel free P558 stainless steel in minimum essential medium, Mater. Lett. 64 (2010) 1476-1479.

[7] J. Buhagiar, L. Qian, H. Dong, Surface property enhancement of Ni-free medical grade austenitic stainless steel by low-temperature plasma carburizing, Surf. Coat. Technol. 205 (2010) 388-395.

[8] M.A. Meyers, A. Mishra, D.J. Benson, Mechanical properties of nanocrystalline materials, Prog. Mater. Sci. 51 (2006) 427-556.

[9] C. Suryanarayana, Mechanical alloying and milling, Prog. Mater. Sci. 46 (2001) $1-184$.

[10] R. Amini, M.J. Hadianfard, E. Salahinejad, M. Marasi, T. Sritharan, Microstructural phase evaluation of high-nitrogen $\mathrm{Fe}-\mathrm{Cr}-\mathrm{Mn}$ alloy powders synthesized by the mechanical alloying process, J. Mater. Sci. 44 (2009) 136148.

[11] E. Salahinejad, R. Amini, M.J. Hadianfard, Structural evolution during mechanical alloying of stainless steels under nitrogen, Powder Technol. 215216 (2012) 247-253.

[12] E. Salahinejad, M.J. Hadianfard, M. Ghaffari, Sh. Bagheri Mashhadi, A.K. Okyay, Liquid-phase sintering of medical-grade P558 stainless steel using a new biocompatible eutectic additive, Mater. Lett. 74 (2012) 209-212.

[13] E. Salahinejad, M.J. Hadianfard, M. Ghaffari, Sh. Bagheri Mashhadi, A.K. Okyay, Fabrication of nanostructured medical-grade stainless steel by mechanical alloying and subsequent liquid-phase sintering, Metall. Mater. Trans. A 43 (2012) 2994-2998.

[14] E. Salahinejad, M.J. Hadianfard, M. Ghaffari, Sh. Bagheri Mashhadi, A.K. Okyay, Compositional homogeneity in a medical-grade stainless steel sintered with a Mn-Si additive, Mater. Sci. Eng. C 32 (2012) 2215-2219.

[15] E. Ma, M. Atzmon, Phase transformations induced by mechanical alloying in binary systems, Mater. Chem. Phys. 39 (1995) 249-267.

[16] M. Mendez, H. Mancha, M.M. Cisneros, G. Mendoza, J.I. Escalante, H.F. Lopez, Structure of a $\mathrm{Fe}-\mathrm{Cr}-\mathrm{Mn}-\mathrm{Mo}-\mathrm{N}$ alloy processed by mechanical alloying, Metall. Mater. Trans. A 33 (2002) 3273-3278.

[17] E.P. Yelsukov, G.A. Dorofeev, A.V. Zagainov, N.F. Vildanova, A.N. Maratkanova, Initial stage of mechanical alloying in the Fe-C system, Mater. Sci. Eng. A 369 (2004) 16-22.

[18] A.H. Taghvaei, M. Stoica, G. Vaughan, M. Ghaffari, S. Maleksaeedi, K.J Janghorban, Microstructural characterization and amorphous phase formation in $\mathrm{Co}_{40} \mathrm{Fe}_{22} \mathrm{Ta}_{8} \mathrm{~B}_{30}$ powders produced by mechanical alloying, Alloys Compd. 512 (2012) 85-93.

[19] Y. Ogino, T. Yamasaki, S. Murayama, R. Sakai, Non-equilibrium phases formed by mechanical alloying of Cr-Cu alloys, J. Non-Cryst. Solids 117-118 (1990) 737-740.

[20] Y. Ogino, S. Murayama, Y. Yamazaki, Influence of milling atmosphere on amorphization of chromium and $\mathrm{Cr}-\mathrm{Cu}$ powders by ball milling, J. LessCommon Met. 168 (1991) 221-235.

[21] H. Miura, K. Omuro, H. Ogawa, Preparation of amorphous high nitrogen iron alloys with ternary additions by mechanical alloying, ISIJ Int. 36 (1996) 951957.

[22] J.R. Davis, Handbook of Materials for Medical Devices, ASM International, 2003.

[23] M.M. Cisneros, H.F. Lopez, H. Mancha, D. Vazquez, E. Valdes, G. Mendoza, M. Mendez, Development of austenitic nanostructures in high-nitrogen steel powders processed by mechanical alloying, Metall. Mater. Trans. A 33 (2002) 2139-2144.

[24] R. Amini, E. Salahinejad, E. Askari Bajestani, M.J. Hadianfard, On the general outline of physical properties of amorphous-nanocrystalline $\mathrm{Fe}-\mathrm{Cr}-\mathrm{Mn}-\mathrm{N}$ alloy powders prepared by mechanical alloying under nitrogen, J. Alloys Compd. 509 (2011) 3252-3256. 